\title{
Espaço de enunciação fronteiriço e processos identitários
}

Eliana Rosa Sturza*

Resumo: A questão das línguas em contato nas zonas de fronteira do Brasil com Argentina e Uruguai tem sido tradicionalmente abordada a partir da descrição dos resultados de contatos entre os sistemas linguísticos do português e do espanhol, bem como das práticas linguísticas resultantes desses contatos. Propõe-se, neste trabalho, uma nova perspectiva de abordagem da questão, considerando o contato das línguas pelo seu modo de circulação na sociedade fronteiriça e pelo sentido que as línguas apresentam para os sujeitos fronteiriços como lugar de significação de sua identidade. Apresentam-se exemplos de funcionamento dos sentidos das línguas para os fronteiriços, em cenas enunciativas que se constituem em espaços de circulação das línguas nas zonas fronteiriças. O habitar e o viver entre línguas dos sujeitos fronteiriços são enunciados na língua da fronteira e significam um processo identitário particular.

Palavras-chave: línguas em contato; fronteira; enunciação; espaço de circulação.

\section{Borderline space of enunciation and identity processes}

Abstract: The issues regarding the borderline areas of contact between Brazil and Argentina and between Brazil and Uruguay have long been investigated from a traditional and descriptive point of view, focusing on the results of the contacts between the Portuguese and Spanish linguistic systems, as well as from the linguistic practices which emerge as a consequence of such contacts. The contacts between those languages and the way they circulate around the borderline society were considered in this study, as well as the meaning conveyed through the languages - for the borderline individuals as an identity locus.. Some examples are given of the way language meanings work for the borderline population in enunciative settings which are language circulation spaces. Dwelling and living between the two languages are elicited in the borderline language and they mean a particular identity process.

Key words: languages of contact; borderline; enunciation; circulation space.

\section{Introdução}

A questão das línguas nas fronteiras e o que a partir dela se formula, no desafio de compreender como se organiza esta zona tão periférica dos Estados

* Professora do Curso de graduação e pós-graduação em Letras, Centro de Artes e Letras, Universidade Federal de Santa Maria (UFSM), RS, Brasil. listurza@gmail.com 
nacionais e, ao mesmo tempo, tão necessária a uma política que se define pelo arranjo dos blocos, dos grupos e das comunidades, traz para discussão, não a geografia como determinante das relações, mas os sujeitos políticos e históricos que habitam as fronteiras, que circulam e se mobilizam nas bordas de uma linha imaginária que divide territórios. Linha esta que lhes permite mover-se e volver. Esse movimento tem colocado as línguas portuguesa e espanhola em relação. As línguas servem aos sujeitos e vice-versa, para assim se significarem como fronteiriços.

Este artigo tem por objetivo discutir o conceito de línguas em contato no escopo do funcionamento enunciativo das línguas praticadas nas zonas de fronteira do sul do Brasil com os países do Prata. Para tanto, a análise que se propóe considera os enunciados produzidos por falantes fronteiriços que vão constituir um espaço de enunciação particular, a que denomino espaço de enunciação fronteiriço. Ao tratar as línguas da fronteira pelo viés enunciativo, tomo como categoria de análise as designações atribuídas pelos falantes às línguas que praticam. As designações, que aparecem nos exemplos que temos recolhido para formar nosso corpus de pesquisa, têm revelado como ao enunciar os sujeitos marcam a fronteira como um lugar identitário.

Desta forma, para tal discussão, busco distanciar-me do enfoque tradicional a respeito do contato de línguas, tema que tem seu lugar teórico firmado na sociolinguística (Appel; Muysken, 1996), além de outros estudos, como os desenvolvidos no campo da geografia linguística, que descrevem as fronteiras linguísticas entre duas línguas, como as realizadas por Rona (1965) sobre a presença do português no norte do Uruguay, mostrando como a extensão e o grau de contato com o espanhol produzia, inclusive, tipos diferentes do que nomeou de Fronterizo. Outros trabalhos relativos aos efeitos do contato linguístico foram os realizados por Elizaincín, Behares e Barrios (1987), resultando na descrição dos DPUs (Dialectos Portugueses del Uruguay). Nesse caso, a noção de mudança linguística foi fundamental para mapear esses dialetos de base portuguesa.

Para abordar, então, o contato linguístico entre o português e o espanhol, na perspectiva teórica que proponho, é necessário levar em conta que, no plano enunciativo, a noção de fronteira linguística seria a da materialidade da língua, na qual as formas nos servem de indicadores da presença de uma língua na outra, quando o espanhol entra no português ou vice-versa. Porém, o contato entre gramáticas das línguas não é suficiente para dar conta de uma abordagem que busca, sobretudo, compreender o funcionamento e os efeitos de sentido que mesmo mudanças nas formas lingüísticas produzem na relação dos sujeitos com as línguas que às quais está exposto, como no caso da fronteira. O que nos interessa é o efeito que a entrada de uma dessas formas produz sobre a 
língua praticada pelo falante quando tomadas de empréstimo da outra língua. Ao serem tomadas de empréstimo e, até mesmo, sendo incorporadas à língua da fronteira, tais formas linguísticas deslocam seu funcionamento e seu significado da língua fonte, passando o falante a atribuir novos sentidos a essas palavras que agarram para si, tornando-as, assim, constitutivas das práticas linguísticas de que dispôem para comunicar-se.

É a sequência enunciativa que nos serve como objeto de análise; nela explicitamos que sentidos políticos, neste caso, marcam a identidade, o que desejam significar os falantes fronteiriços ao enunciarem desta forma: na mistu$r a$; na mescla; no fronterizo, no portunhol; no DPU. É, portanto, nesse sentido, que se entende a fronteira não restringida ao limite do quanto há de contato de uma língua em outra, pela presença de formas linguísticas tomadas de empréstimo ou já incorporadas, legíveis ou audíveis na materialidade linguística, sobretudo porque, ao serem enunciadas, significam que estão condicionadas ao que foi se constituindo historicamente na fronteira social.

Parte-se, então, da ideia de que fronteiras e sujeitos se significam ao moverem-se entre uma língua e outra, decorrentes de uma mobilidade social, atravessada pelas condiçôes sócio-históricas que vão impondo a construção de uma nova territorialidade. Ao levar em conta a fronteira social, a questão da identidade dos fronteiriços emerge e explicita-se também na língua, pois, na frontei$\mathrm{ra}$, as línguas (e aqui estamos tratando de duas línguas nacionais em contato) são constitutivas das relações dos sujeitos com o seu espaço social.

A fronteira a que nos referimos aqui se caracteriza por uma mobilidade social que está balizada por uma relação contraditória, por vezes de conflito, outras vezes por integração, no que já me referi anteriormente como característico da vida cotidiana, do seu "ir e vir" (Sturza, 2005). Tais reflexōes, sobretudo, têm relevância para, por exemplo, explicitar o papel do ensino das línguas nacionais dominantes, português e espanhol, vistas como línguas próximas e compreendidas como constitutivas dos modos de representação das identidades dos sujeitos fronteiriços.

\section{Fronteira: espaços sociais, espaços geopolíticos e espaços de enunciação}

Se a fronteira constrói uma nova territorialidade e essa noção conceitual e se formula a partir de um quadro sociológico, não apenas geográfico e/ou geopolítico, em curso o desejo dos sujeitos fronteiriços de marcar seus lugares identitários. Desse modo, os processos identitários enunciar-se-iam na língua e pela língua, e significar-se-iam através dos modos e dos lugares onde essa identidade ou desejo dela se marcassem na enunciação. Porém, enunciar nas 
línguas, seja em português, em espanhol ou em alguma "mescla" de ambas, nas condições sócio-históricas e econômicas da fronteira, especialmente as do extremo sul do Brasil com a Argentina e o Uruguai ${ }^{2}$, leva-nos à reflexão de que aí se constitui um espaço de enunciação diferenciado, que já mencionei como Espaço de Enunciação Fronteiriço (Sturza, 2006).

Vale ressaltar, no entanto, que essas fronteiras têm histórias locais distintas, embora apresentem uma série de traços culturais, costumes, códigos sociais comuns. Em algumas zonas há maior concentração urbana, colocando mais comunidades e grupos sociais em contato, de maneira mais contínua, mais regular e mais intensa. Essas características, evidentemente, não se repetem de igual modo em outras zonas da fronteira. Logo, é preciso esclarecer dois conceitos que são fundamentais para abordar a relação língua e sujeitos, dado o entorno em que se configura a sociedade fronteiriça e suas peculiaridades: espaço de enunciação e línguas em contato.

Os enunciados que trazemos para ilustrar como o sujeito fronteiriço se enuncia diferente nesse espaço diferente é o que permite focalizar os efeitos do dizer dos falantes e não as formas empregadas, usadas por eles. Nesse sentido, o contato é concebido como constitutivo da língua do fronteiriço. As formas e as estruturas linguísticas indicam-nos a presença do contato, tendo uma outra função na análise que procedemos. Desse modo, não tratamos de gramáticas de línguas em contato, porém de um modo de enunciar particular, o de quem habita a fronteira, que é tomado pelas línguas, pelas condições nas quais essas línguas vão funcionando, onde elas circulam mais ou menos, em que espaços elas têm maior domínio de circulação e o que isso representa para a constituição de um espaço de enunciação que não se repete e que não vai se reproduzir em outros espaços de enunciar do português ou do espanhol. Principalmente, que contribuição apresenta uma abordagem que desloca esse conceito de línguas em contato, para pensar o contato como constitutivo dessas línguas da fronteira. O contato enunciativo, aquele em latência na enunciação do fronteiriço, é o que marca o irrepetível do espaço de enunciação fronteiriço, revelador do modo de circulação das línguas e suas relações com os sujeitos falantes. Falantes esses que se movem em vários lugares, em diferentes cenas, inclusive em instâncias nas quais as exigências se dão invariavelmente no quadro da língua nacional, deixando de fora essa língua da fronteira, como a da escola. Logo, a língua da fronteira é essa que se enuncia nesse espaço de circular e nesse espaço de habitar.

\footnotetext{
I. Aqui, neste momento, refiro-me apenas ao processo, não à designação e/ou nome dado a essa mescla, seja pelos falantes, seja pela comunidade científica.

2. Os exemplos utilizados, ao longo do texto, foram coletados nessa zona de fronteira.
} 
Das fronteiras do sul do Brasil, ao longo do sul e do oeste do Rio Grande do Sul, encontramos alguns pares de cidades correspondentes a cidades da Argentina e do Uruguai. Essas comunidades, fincadas em ambos os lados das fronteiras geopolíticas, estabelecem suas relaçōes cotidianas, na maioria das vezes, por processos de inter-relaçôes construídas nas bases locais. Quer dizer, os sujeitos entram em contato por necessidades de toda ordem, criam modos de intercomunicar-se como, por exemplo, mesclar duas línguas para melhor interagir com o seu vizinho, o seu cliente, o seu visitante, o seu parente.

$\mathrm{Na}$ fronteira Rivera - Livramento (Schäffer, 2002, p. 38) há uma situação de conurbação, em que o centro das atividades cotidianas ocorre sobre a linha divisória, pois...

a proximidade da linha' promoveu o comércio, em especial o trânsito de determinadas mercadorias. O Comércio da fronteira traçou o desenho das duas cidades e estabeleceu a área de circulação, o centro efetivo, não aquele, não aquele da administração ou o histórico, mas a 'linha'. Junto à linha estão os estabelecimentos comerciais, os doleiros, está a vida da cidade. (autoria dos grifos)

Nesses locais de comércio, onde pessoas circulam, conversam, a prática de línguas e a circulação delas têm uma outra dinâmica. É muito corrente falar uma língua ou outra, em situações diversas. De tal maneira, o mais frequente que se observa é que cada um fala sua língua, mantendo um grau de intercompreensão, os sujeitos são capazes de fazer-se entender e a comunicação resulta fluida e eficiente, independentemente do nível de domínio do código linguístico (da gramática) que cada um tem da língua do outro. Há registros de muitas cenas nesse espaço de circulação das línguas.

Defino cena como a cena enunciativa, ou seja, é aquela em que os elementos condicionantes constituem os sentidos dos enunciados que a compõem. A cena em que os sujeitos se enunciam, significando-se no espaço de enunciação fronteiriço. Portanto, uma cena no comércio de Rivera ou na baixada ${ }^{3}$ de Uruguaiana está configurada por quantidades de cenas enunciativas. Embora com pouca pesquisa sobre seu funcionamento nas práticas linguísticas fronteiriças, elas nos apontam haver tendências enunciativas que só podem ocorrer pelo contato do português e do espanhol nas zonas fronteiriças e em determinados espaços de circulação. Cenas que organizam o funcionamento dos sentidos segundo os espaços de circulação dessas línguas, como no posto de fiscalização aduaneiro, nos festivais de folclore, nas festividades culturais, nas festas familiares (casamentos, batizados, aniversários).

3. "Baixada" ou "baxada" é o nome popular para a zona de comércio informal de Uruguaiana em que há uma grande circulação de argentinos e uruguaios no local. 


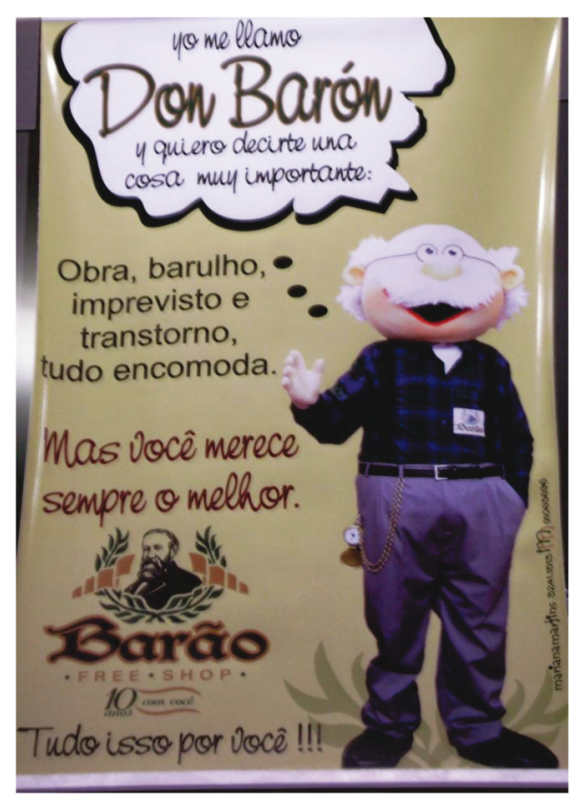

Figura I. Banner em loja em Rivera, escrito nas duas línguas. Isto nos ilustra como se organiza esse espaço de circulação e enunciação das línguas, que significa como os sujeitos e as línguas estão afetados pelas condições sócio-históricas e econômicas da fronteira como espaço social

As cenas compostas por várias sequências enunciativas funcionariam ainda como um modo de apresentar, em um plano mais micro, como operariam as tendências enunciativas de uma língua na outra, resultantes do contato linguístico entre o português e o espanhol. Tal como já apresentaram Sturza e Fernandes (2009):

[...] uma tendência enunciativa também marca o dizer de um indivíduo quando este se expressa por meio de uma língua estrangeira ou, pelo menos, uma língua que não seja comumente empregada na maioria das situaçōes em que se envolve o indivíduo. Portanto, a tendência enunciativa de uma língua verificase nitidamente em outra quando o falante de uma língua $\mathrm{X}$ se comunica por meio de uma língua $Y$, mesmo quando tal falante possui um conhecimento muito avançado da língua $Y$.

Para ilustrar, nos postos de gasolina de Paso de Los Libres (fronteira BrasilArgentina), brasileiros solicitam a quantidade e o tipo de gasolina, pagam com dinheiro ou cartão, negociando com o frentista argentino em português. A conversa flui, costurada pelos sentidos que se engendram no plano da intercompreensão, por meio desses atos de linguagem que expõem os sujeitos às línguas. 
Em outro ponto da zona fronteiriça, o contato linguístico português-espanhol nos free shops de Rivera (fronteira Brasil-Uruguai) ocorre do seguinte modo: muitos vendedores que trabalham no comércio local são brasileiros, falam em português com os colegas uruguaios e estes, por sua vez, quando nos atendem, aos brasileiros, falam também em português. Em seguida, continuam falando, em espanhol, com seus colegas vendedores brasileiros. Este é um quadro em que as línguas se entrecruzam.

Bastante ilustrativo nas cenas enunciativas desse espaço de circulação das línguas tem-se no exemplo, no lado brasileiro da fronteira, quando um dizer na língua/ou línguas está constituído por um discurso sobre língua. Os sujeitos fronteiriços explicitam que sentidos essas línguas têm para eles quando elas funcionam nesses ambientes de circulação, como o comércio informal. Na prática da língua, em que os falantes dizem o que as línguas representam para eles, a mistura é a designação mais recorrente dada à língua praticada. Nos vários depoimentos sobre a língua que se fala no comércio local ${ }^{4}$, a mistura apresentase significada pela sua função imediata de facilitar a comunicação, ao mesmo tempo significando uma língua de.

Essa língua de é compreendida como própria do lugar, ou seja, da fronteira, marcando a nova territorialidade, o terceiro território, nem lá nem cá. Neste nem lá e nem cá cabe a mistura. O entrelínguas que remete ao processo identitário de sujeitos que estão entre espaços e línguas. E, tal como a mistura das línguas, é um processo incompleto, em construção, irregular, instável. Pergunta-se, então, seria tal processo uma representação na língua dos processos identitários em curso?

Como construções sociais, as representaçôes que os sujeitos deixam na língua relacionam-se com aquilo que eles constroem como significativo de suas marcas identitárias, assim como a memória e o imaginário que fazem parte da fronteira concebida como um terceiro território, alargado nos seus limites cartográficos. O deslocamento humano, a migração, as inter-relações fazem da fronteira muito mais um espaço social periférico que tão somente o confim do Estado, conceito que toma a fronteira como esvaziada de sujeitos históricos, políticos e sociais. Por conseguinte, identificar-se com essa realidade à parte é traduzir-se nela.

No Brasil, de acordo com Oliven (2006, p. 57-58), a afirmação das identidades regionais

4. Esses depoimentos foram recolhidos por Emannuelle Bär Coutinho. Ver. O uso do portunhol no comércio informal da cidade Uruguaiana na Fronteira Brasil -Argentina. Monografia de Final de Graduação. Entrelínguas / Letras - UFSM — Santa Maria - RS, 2009. 
[....] pode ser encarada como uma reação a uma homogeneização cultural e como uma forma de salientar diferenças culturais. Essa redescoberta das diferenças e a atualidade da questão da federação numa época em que o país se encontra bastante integrado do ponto de vista político, econômico e cultural sugerem que no Brasil o nacional passa primeiro pelo regional.

Os sujeitos fronteiriços seriam, portanto, aqueles que estão situados dentro da faixa de fronteira territorial, que está demarcada em $150 \mathrm{~km}$ de extensão para dentro do território brasileiro. No entanto, essa identificação regional não ocorre só pela demarcação do território, mas também por traços sociais e culturais comuns. No Rio Grande do Sul, por exemplo, essa zona tende a coincidir e ser reconhecida como a metade sul do estado, uma porta de entrada para os limites fronteiriços do Brasil com Argentina e Uruguai. Deste modo, remetendo a uma série de imaginários sobre o tipo social, muito associado à figura do gaúcho, aos costumes mais rurais, à língua, um português mais influenciado pelo espanhol.

Nesse sentido, o uso das línguas, ou mais destacadamente, ao que os próprios sujeitos fronteiriços reconhecem como uma mistura, está relacionado a um fator identitário, em afirmações tais como ${ }^{5}$ :

a) puedo hablar en fronterizo para destacar mejor mi región;

b) porque es el idioma que nos identifica como fronterizos;

c) o idioma que mais se usa do lado de cá, na fronteira, é esse portunhol pra gente se entender.

Os enunciados a, b e c, em que o sujeito remete à língua um sentido de identidade - destacar, identifica, pra gente se entender -mostram como em fronteiras diferentes - $a$ e $b$ são de Rivera (Uruguai) e $c$ é de Bagé (Brasil) —, embora enunciando cada um na sua língua, o que se tem significado é um sentimento de pertencimento a um espaço social comum, a uma comunidade. Essa marca linguística (gente) na língua portuguesa opera na enunciação; muito mais do que eu + os outros, ela significa nós, os fronteiriços, os que habitamos esta zona social comum.

O que, para a sociolinguística, é uma revelação a respeito da atitude de um falante frente à língua que usa (exemplo a e b) como apenas uma declaração, ainda assim o sentido entra para explicar o vínculo da língua com a identidade. Segundo Apple e Muysken (1996, p. 29-30):

5. Estes exemplos foram apresentados nos trabalhos de Pasi Puranen, em sua tese de doutorado na Universidade de Helsinki, Finlândia, em 1999 e na dissertação de mestrado de Isaphi Alvarez,no PPGLetras - UFSM - RS, em 2009. 
El hecho de que las lenguas no son sólo instrumentos objetivos y socialmente neutros que transmiten un significado, sino que están relacionadas con las identidades de los grupos sociales y étnicos, tiene consecuencias para evaluación social de las lenguas y para las actitudes que éstas provocan. Aunque quizás debiéramos expresarlo de otra manera: Si hay una relación intensa entre lengua e identidad, esta relación debería manifestarse en las actitudes de los indivíduos hacia esas lenguas y sus usuarios.

Nesses enunciados, o que se explicita é uma posição política do sujeito sobre suas relações com o outro. Dizer na língua é significar essa relação identitária, inclusive, designando a língua do contato. Língua que é constitutiva desse sujeito nas suas relações sociais, porque na e pela língua os fronteiriços enunciam o que os identifica como tal. Como diz Oliven (2000, p. 169): "todos esses processos envolvem atribuição de significados às ações humanas, a descoberta de diferenças, a apropriação e reelaboração de manifestações culturais, a ressemantização, etc.”

O ressemantizar é crucial aqui para pensar a designação. Portunhol, no enunciado $c$, já funciona na língua como um nome dado a essa língua que aí se fala, remetendo ao processo de interface que reúne graficamente o nome das línguas e simboliza a língua pra gente se entender.

A língua do entendimento é a língua do comunicar-se com o outro. A que pressupooe a existência de um interlocutor; embora do lado de cá, não é da fronteira, mas na fronteira. Esse lugar fincado não parece tão delimitado porque o sujeito não nomeou a cidade onde mora, mas o lugar de onde é. A fronteira, como esse espaço ampliado socialmente. E aí entra a necessidade de ele se entender com os hermanos.

O enunciar projetando o outro é da natureza da linguagem humana. Benveniste (1995, p. 286) afirma:

A linguagem só é possível porque cada locutor se apresenta como sujeito, remetendo a ele mesmo como eu no seu discurso. Por isso, eu propõe outra pessoa, aquela que, sendo embora exterior a "mim", torna-se meu eco - ao qual digo tu. A polaridade das pessoas é na linguagem a condição fundamental, cujo processo de comunicação, de que partimos, é apenas uma conseqüência totalmente pragmática. (autoria do grifo)

Dado que nessas fronteiras se configura um quadro de intercompreensão linguística, há possibilidade de que ele se estruture, do ponto de vista enunciativo, por funçôes pragmáticas que levam os sujeitos a distribuir-se en- 
tre línguas, de diferentes modos: falando cada um na sua língua; falando, às vezes, segundo a competência linguística, com alternância de códigos; ou utilizando uma mistura das duas línguas. As cenas enunciativas apresentadas anteriormente ilustram essas situaçôes. Qualquer modo de distribuição a que se atribui o sujeito funciona para o falante com possibilidades de marcar sua identidade ou indicar o processo identitário no qual está inserido ou que o constitui, independentemente da fronteira geográfica na qual ele se encontre.

Se tomarmos o espaço de enunciação fronteiriço como definição válida no campo dos estudos enunciativos, poderemos pensar que os contatos linguísticos nas fronteiras - sem determo-nos apenas na descrição das formas e das suas mudanças - têm subjacente um contato social que se estrutura muito mais pelas funçôes pragmáticas da linguagem e que, portanto, qualquer língua em contato, consideradas as condições sócio-históricas da situação que as produziu, tem por constitutivo uma função primeira, qual seja, a de projetar a intercompreensão; acima, inclusive, de termos ou não domínio dos códigos linguísticos.

De acordo com Guimarães (2006, p. 47-48),

[...] as línguas funcionam segundo o modo de distribuição para seus falantes. Ou seja, línguas não são objetos abstratos que um conjunto de pessoas em algum momento decide usar. Ao contrário, são objetos históricos e estão relacionadas inseparavelmente daqueles que as falam. Não há língua portuguesa sem falantes desta língua, e não é possível pensar a existência de pessoas sem saber que elas falam tal língua e de tal modo. É por isso que as línguas são elementos fortes no processo de identificação social dos grupos humanos.

Nesse "Desconhecido território das práticas linguísticas fronteiriças" (Sturza, 2005) há, pelo menos, três modos de seus falantes - tomados como sujeitos históricos, assim como suas línguas tomadas como objetos históricos por meio dos quais se identificam como pertencentes à fronteira como uma nova territorialidade - de organizarem-se cotidianamente através de diversas relações que propiciam um intercâmbio contínuo, até para o surgimento de um entrecruzamento de dizeres, numa pluralidade de práticas linguajeiras que vão configurando um espaço de enunciação (Sturza, 2006).

Uma das designaçōes mais instigantes a respeito do modo de falar dos fronteiriços foi dada por um falante na fronteira Brasil-Uruguay, na cidade brasileira de Bagé. Perguntado sobre como se falava naquela fronteira do extremo sul do Brasil, em que a passagem de um lado ao outro da chamada linha se desenha, define-se e inicia-se na imaginação de cada um porque, como tantos 
outros fronteiriços, é ele como sujeito que decide onde começa e/ou termina a linha, onde deseja estabelecer o lá e o cá, disse que aí nesse lugar se fala apaisanado.

Carregado de sentidos, esse enunciado projeta interpretações sobre a constituição dos processos identitários dos sujeitos fronteiriços a partir do modo como eles se relacionam com as línguas que os afetam, que os atravessam, tal como os atravessam as linhas imaginárias da fronteira. Esse lugar de enunciar é assim, cheio de mobilidades, que vão abrindo espaços de entrada de uma língua na outra. É, nesse sentido que busco também mobilizar o conceito de línguas em contato, para redimensioná-lo e tomá-lo como próprio na medida em que constitutivo do funcionamento enunciativo das línguas.

Apaisanado, síntese desde jogo do ir e vir, do aproximar e do distanciar, do não lugar que o estar na fronteira impõe aos seus habitantes, entreverados entre uma língua e outra, revela-se como resultado de um estado de ser. Muitas vezes, colocando-os em enfretamentos nos espaços institucionais e formais de uso da língua, por exemplo, na escola, quando a língua que o significa como sujeito, a língua de dentro de casa, a familiar, a da rua, a do comércio, a da linha (especialmente Rivera-Livramento), é estigmatizada, é carregada de preconceitos, de negação da identidade fronteiriça, desse viver entre línguas. $\mathrm{O}$ falante, como tomado por essas línguas, utiliza-as, marcando seu lugar político e identitário.

Outra situação de relação identitária que se aloca na distribuição que o falante dá para cada língua com a qual se relaciona é a de um adolescente, vendedor de cartôes de Natal na rua Sarandi, rua principal de Rivera. Perguntado sobre se aprendia português na escola, respondeu que na escola aprendia em português e espanhol. E acrescentou: em casa, com meus pais, falamos em portunhol.

$\mathrm{O}$ estar entre as línguas, somado à implementação de projetos - como ensino dual português-espanhol - vai intervindo sobre essas relações e criando um novo contexto educacional. Observa-se, a partir daí, um redimensionamento do lugar que as línguas passam a ocupar para os sujeitos, e os sentidos políticos que elas têm, pelo dizer, enunciar a identidade fronteiriça.

\section{Cartografia de uma questão}

Os conflitos dessas relações entre línguas e sujeitos, que emergem nas suas enunciaçōes, são interpretados em muitos exemplos registrados em falas, conversações e depoimentos para pesquisas de monografias de final de graduação, trabalhos de iniciação científica, dissertações de mestrado e teses de doutorado. Esses registros fazem parte de um conjunto de falas, que constituem um 
corpus para análise dessas relações entre sujeitos e línguas em situações nas quais as próprias línguas em contato vão configurando fronteiras enunciativodiscursivas, que se materializam nas línguas praticadas pelos fronteiriços. É importante, nesse sentido, destacar ainda que há dois modos de designar essas práticas linguísticas: o falante fronteiriço define e nomeia seu modo de falar, e o falante incorpora o nome já dado pela comunidade científica. Essas formas de designar, que vão aparecer nos enunciados exemplificados aqui, enunciam esse sujeito que se identifica com a interface das línguas. Interface esta que espelha o modus vivendi da fronteira, especialmente de fronteiras tão particulares nas suas imbricaçóes sociais, econômicas e culturais, caso de SantAnna do Livramento e Rivera.

Refiro-me a esse modus vivendi, retomando a noção de habitat fronterizo de Ana Camblong. Considerando que habitar a fronteira leva os sujeitos a entrarem em um modus vivendi próprio, com seus códigos, com suas identificações, com suas contiguidades - tanto quanto uma linha imaginária na qual não se identifica início e fim - em que há uma rotina de entrecruzamentos -ou de "cruces", impulsionando a dinâmica de uma vida em fronteiras, há um conjunto de peculiaridades e modos de organização que leva a pensar em uma sociologia da fronteira.

A fronteira, concebida do ponto de vista mais social que geopolítico, é notadamente um espaço de confluências, sejam elas por integração, sejam elas por oposição de todo tipo, política, ideológica, econômico-social. O comércio, os negócios locais têm um importante papel, qual seja o de colocar em interação espaços nacionais diferentes, desde fuera hacia adentro (Grimson, 2005). Quer dizer, pela condição mesma de ser um espaço periférico está a fronteira à frente das rivalidades locais, regionais e nacionais.

Segundo Grimson (2005, p. 23):

Desde esa perspectiva, las poblaciones fronterizas son concebidas solo como víctimas de las políticas de nacionalización del estado y no como agentes activos de la construcción de sus propias afiliaciones identitarias.

As políticas de avizinhamento social na fronteira predispõem os sujeitos a entrar em contato por diferentes vias. O comércio, ao longo da história, beneficiou-se das situaçōes econômicas favoráveis ou desfavoráveis para impulsionar os negócios locais. Este foi o caso de Uruguaiana no fim do século XIX e princípio do século XX e, de tempos em tempos, a situação repete-se e reverte-se em Rivera e Livramento, na dependência do fluxo cambial. O fator econômico impulsiona a vida local. Nos exemplos trazidos aqui, esse é local onde a circulação de falantes é mais dinâmica, portanto, o contato tende a intensificar-se. 
A dinâmica que se desenvolve nessas atividades, que se caracterizam por ser da subexistência humana, vão colocando as línguas em um atravessamento, em cruces e vão deslocando o seu papel de representação como língua do Estado, porque aí já é a língua do lugar, da necessidade, da relação. A representação é outra, é a língua de fronteira, definida por ser a que resulta da interface entre duas línguas em contato (português e espanhol), por ser enunciada desde esse lugar particular, por ser reconhecida na mistura, porque funciona para interagir com o outro. Tal como vemos nestes exemplos:

a) Nós temos as duas línguas muito próximas, então a gente usa a mescla quando fala com os hermanos.

b) É uma língua que precisamos ter para lidar com uruguaios e argentinos.

c) A mistura do português e do espanhol típicos da fronteira.

d) Portunhol é um idioma inventado, para que haja comunicação entre as partes; assim como os brasileiros, os argentinos também tentam com o portunhol se expressar.

Para finalizar, nos enunciados citados acima, destaco como definem os falantes essa prática linguística que resulta de um estar entrelínguas, porque é de um habitar a fronteira. A designação mais frequente nos exemplos recolhidos tem sido Portunhol, muitas vezes associada à ideia de mal falar uma língua. No entanto, reiteradas nas falas pela noção de que essa prática é a síntese de duas línguas que entram em contato, embora nem se saiba bem o quanto sua materialidade linguística tem de uma ou outra língua. O Portunhol é esta mescla, mistura que se define por um estado de processo, em constante trocar-se, misturar-se. Por outro lado, do ponto de vista do seu funcionamento enunciativo-pragmático, é uma língua que funciona sempre que projetada para um interlocutor, a saber, não desconhecido, não tão estrangeiro, mas com quem é preciso ampliar o contato, é necessário compreender. É, nesse sentido, que essa língua da fronteira se significa como "língua de...", ainda por preencher, cabendo todas as identidades, as construídas, as em processo de construção.

\section{Referências bibliográficas}

ALVAREZ, I. Falar apaisanado: uma forma de designar as línguas na fronteira. 2009. Dissertação (Mestrado em Letras) - Universidade Federal de Santa Maria, Santa Maria - RS.

APPLE, R.; MUSYSKEN, P. Bilingüismo y contacto de lenguas. Barcelona: Ariel Lingüística, 1996.

BÄR, E. C. O uso do portunhol no comércio informal na cidade de Uruguaiana na fronteira BrasilArgentina. 2009. Monografia de conclusão de curso (Graduação em Letras Espanhol)- UFSM - Santa Maria. 2009.

BENVENISTE, E. Problemas de lingüistica geral I. Campinas - SP: Pontes, 1995. 
CAMBLONG, A.M.. Habitar la frontera, un viaje perpetuo a lo paradójico. Lima-Peru. In: CONGRESO LATINOAMERICANO DE EDUCACIÓN INTERCULTURAL BILÍNGÜE, 5., 6 a 9 de agosto de 2002, Lima/Peru.

ELIZAINCIN, A.; BEHARES, L. E.; BARRIOS, G. Nosfalemo brasilero. Dialectos portugueses en Uruguay. Montevideo: Amesur, 1987.

GUIMARĀES, E. Semântica do acontecimento. Campinas — SP: Pontes, 2002.

GUIMARÃES, E. Enunciação e política de línguas no Brasil. Revista Letras - Espaços de Circulação da Linguagem, n. 27, jul./dez. 2006.

GRIMSON, A. Cortar puentes, cortar pollos: conflictos económicos y agencias políticas en Uruguayana (Brasil)-Libres (Argentina). In: OLIVEIRA, R. C.; BAINES, S.G. (Org.). Nacionalidade e etnicidade em fronteiras. Brasília: Editora UNB, 2005. p. 21-54.

OLIVEN, R. A parte e o todo. A diversidade cultural no Brasil-Nação. 2. ed. Rio de Janeiro: Vozes, 2006.

OLIVEN, R. Modernidade e identidade nacional. In: KERN, A. A. (Org.). Sociedades iberoamericanas. Porto Alegre: Editora PUCRS, 2000. p.153-169. Reflexôes e Pesquisas Recentes.

PURANEN, P. Las actitudes linguísticas y el prestigio del portuñol en la ciudad de Rivera. Finlândia,Universidade de Helsinki, 1999.

RONA, J. P. Dialectos portugueses del norte del Uruguay. Montevidéu: Adolfo Lunardi, 1965.

SCHÄFFER, N. O. A especificidade funcional da urbanização na fronteira meridional do estado. In: RECKZIEGEL, A. L. S.; FÉLIX, L. O. (Org.). RS: 200 anos definindo espaços na história nacional. Passo Fundo - RS: UPF, 2002. p.31-41.

STURZA, E. Línguas de fronteira: o desconhecido território das práticas lingüísticas nas fronteiras brasileiras. Revista Ciência e Cultura. SBPC. ano 57, n. 2, abr./maio/jun. 2005. Temas e Tendências: Línguas do Brasil.

STURZA, E. Linguas de fronteiras e politicas de línguas: uma história das idéias lingüísticas. 2006. Tese (Doutorado em Letras). IEL/UNICAMP. Campinas, 2006.

STURZA, E.; FERNANDES, I. C. A fronteira como novo espaço de representação do espanhol no Brasil. Revista Signo \& Seña, Buenos Aires: UBA, 2009.

Recebido em 04 de fevereiro de 2010 e aprovado em 07 de julho de 2010. 